\title{
Integración del Psicodrama con otras líneas teóricas
}

RESUMEN: Se describe la integración del psicodrama con otras psicoterapias. Se analizan las relaciones con el psicoanálisis, gestalt, sistémica y terapias corporales. Se ilustran con diversos ejemplos clínicos que muestran la manera correcta de integrar las diversas teorías. Se concluye que la integración enriquece la práctica, la hace más flexible y se adapta mejor a las necesidades de los clientes.

PALABRAS CLAVE: Gestalt. Integración. Psicoanálisis. Psicodrama. Sistémica. Terapias Corporales
SUMMARY: On describe the integration of psychodrama with other psychotherapies. The relationships between psychodrama, psychoanalysis, gestalt, systemic and body therapies are suggested with several clinic examples. With that addition, the pratice become more flexible and the clients can gets their goals.

KEY WORDS: Body therapies. Gestalt. Integration. Psychoanalysis. Psychodrama. Systemic theory.

Todo el mundo es una escena

Sobre la cual los hombres y mujeres son pequeños actores Que vienen y van.

Un hombre ha de hacer muchos papeles en la vida.

SHAKESPEARE

\section{1- Introducción a las líneas teóricas}

Las psicoterapias grupales se agrupan en un continuo que oscila entre el predominio verbal y el no verbal de la siguiente manera (1): terapia de grupo psicoanalítica, dinámica de grupos, psicodrama, bioenergética y técnicas corporales.

Los marcos teóricos de referencia de estas orientaciones son muy diferentes y se resumen en: empírico-estadístico, psi- coanálisis, teoría de los roles y teoría de los sistemas (1).

Básicamente, la psicoterapia de grupo psicoanalítica se apoya en el psicoanálisis; aunque Freud nunca realizó un grupo de psicoterapia y su orientación era individual e intrapsíquica. Por ello recurre a la teoría topológica del campo de Lewin, en la que se basa la gestalt preconizada por Perls. La posición de los miembros del grupo, la consideración del grupo como 
una totalidad diferente del mero agregado de los individuos y las transferencias laterales entre los miembros del grupo son algunos aspectos específicos del grupoanálisis

La dinámica de grupos se fundamenta en el modelo empírico-estadístico, pero también se nutre de la teoría de los sistemas y de la comunicación humana. Interesa la cantidad y la calidad de los mensajes, es decir, su finalidad dentro del grupo. Sus trabajos han servido para el análisis de los factores terapéuticos de los grupos y de otros fenómenos grupales como la cohesividad.

El psicodrama sostiene que el Yo proviene de los roles que el sujeto desempeña a lo largo de su vida y no al revés, como afirma el psicoanálisis. La teoría de los roles se instaura como una serie de círculos concéntricos. En el centro se encuentran los roles psicosomáticos (Dormilón, Comilón, Mingidor, Llorón, etc.). Por fuera, los roles familiares (padres, hermanos, vecinos, compañeros, etc.). En el exterior, los roles sociales que generalizan y simbolizan los roles familiares. Define el nacimiento como el primer momento creativo del niño; sin embargo para la teoría psicoanalítica es un trauma. Concibe el infante como un ser creador que se ve constreñido por las leyes inexorables de la civilización, lo que le convierte en una conserva cultural, en lugar de un innovador. Se centra más en el encuentro interhumano que en las interioridades psíquicas del sujeto, aunque también las tiene en cuenta. Del psicoanálisis recoge que las psicosis se producen cuando existe una indiferenciación entre fantasía y realidad.
Su propuesta de intervención es muy original en tanto invita al psicótico a delirar en el espacio imaginario de la escena (2) en lugar de hacerlo en la realidad. También recurre a los modelos empírico - estadísticos y a la teoría de los sistemas.

La bioenergética se inspira en las teorías de Reich y por lo tanto se basa en el psicoanálisis. Su creador fue Lowen. A los conceptos de coraza caracterial de Reich añade un diagnóstico corporal. Éste permite intervenir en las rigideces musculares que las neurosis y psicosis dejan como impronta en los seres afectos. La respiración, la relajación y el movimiento son modalidades no verbales de actuar con el cuerpo. No requieren el uso de la palabra y por lo tanto están muy indicadas cuando prima la inhibición, el hospitalismo ó la incapacidad para expresarse. El uso de ejercicios no significa que se menosprecie la comunicación verbal. Se invita a los asistentes a comunicar verbalmente sus experiencias y emociones; lo mismo sucede en la vegetoterapia caracteroanalítica de Reich, que es su antecesora.

Las técnicas corporales como el masaje sensitivo gestáltico se basan en conceptos psicoanalíticos como la necesidad de apego de los seres humanos. También tiene el influjo de la teoría de los roles. Algunos aspectos filosóficos son de origen oriental, como la búsqueda de la armonía y relajación, y otros son extraídos de la fisioterapia. La relación suele ser dual: asistente - cliente. Cuando se trabaja en grupo suele ser con ejercicios corporales, dentro de un campo teórico más amplio. 
Las diferencias de conceptualización y la práctica tan diversa han propiciado un desarrollo paralelo e independiente de las corrientes teóricas antes citadas. Predomina una notable ignorancia de unas respecto de las otras y la consiguiente dificultad para ensamblarlas, sobre todo las más distanciadas entre lo verbal y lo corporal.

Se escoge el Psicodrama por situarse a medio camino entre el predominio verbal y no verbal. Las tendencias han sido seleccionadas en virtud de su relevancia y aportación a las otras modalidades de intervención. No es una lista excluyente, ya que la integración se puede hacer con otras aportaciones y con resultados muy favorables, como por ejemplo con el modelo cognitivo - conductual.

Los objetivos de este trabajo son mostrar la riqueza de la integración de diversas técnicas y la forma correcta de realizarla. El conocimiento de varias orientaciones dificulta una creencia ciega en una sola modalidad de intervención. Para todo ello se recurre a diversos ejemplos clínicos que ilustran dicho quehacer. Parafraseando a Freud: Se abandona el oro puro del psicoanálisis para realizar una aleación con las psicoterapias, que mejore la dureza y rendimiento de nuestra intervención.

\section{2- El psicodrama y la integración}

Moreno fue un creador nato y como tal diseminó en el mundo múltiples ideas. Su dispersión hizo que parecieran inconexas y, en ocasiones, carentes de sentido. Su aluvión de sugerencias ha sido tan grande que desbordó a sus seguidores y se co- rre el riesgo de cuestionar la parte por el todo, como hacen sus detractores. El padre de la psicoterapia de grupo, el psicodrama y la sociometría (3) no se preocupó de crear un cuerpo teórico armónico y cerrado. En ocasiones sus escritos parecen contradictorios. Sus ideas nos arrastran como un torbellino de lo individual a lo familiar, del grupo a la comunidad y de las naciones al mundo con sus paradojas (cuanto más álgido es el conflicto antes se rompen las negociaciones, que son la única manera de resolver los desacuerdos entre las partes beligerantes).

En su madurez, el creador del psicodrama se preocupó mucho por la apropiación de sus ideas que, sin referencias a su creador y despojadas de su sentido original, eran presentadas como otiginales. Así sucede con el modelado conductual, también con algunos momentos de la gestalt y en los aspectos dinámicos se subraya la famosa polémica con otro gran pionero de la psicoterapia de grupo, Slavson. Ello no fue obstáculo para que Moreno creara la IAGP junto con grupoanalistas y dinámicos e impulsara una visión amplia de la psicoterapia de grupo, abierta a otras corrientes y avances científicos y tecnológicos $(1,3)$.

Para perfilar mejor la realimentación y desarrollo, entre el psicodrama y otras orientaciones, Moreno sólo pedía que se respetara su filosofía. Ésto es, la historia en acción de forma eontánea y creativa en un tiempo presente, sin sentirse oprimido por el pasado o agobiado por el futuro (4). Por espontánea se entiende una respuesta apropiada a una situación nueva $\mathrm{u}$ original a una situación antigua y resuel- 
ta. Si la respuesta es espontánea ya resulta creadora por definición. No olvida el tiempo pretérito ni sobrevalora el porvenir. Ambos son vividos en el "aquí y ahora" del espacio imaginario de la escena. Es como si Edipo vuelve a vivir la escena de la encrucijada de caminos y en lugar de elegirlos al azar, con resultado trágico, ensaya otras soluciones. Gracias a ellas, él toma las riendas de su vida y se hace responsable de su resultado, en lugar de víctima de los dioses o del destino.

Algunos pensarán que la espontaneidad y la creatividad están reñidas con los modelados perfectamente organizados de la orientación conductual. Las escenas organizadas para evaluar vendedores o el uso del juego de roles para preparar y examinar en profesiones basadas en relaciones humanas (medicina, psicología, psicopedagogía, enfermería, trabajo social, educación social, etc.) desmiente este prejuicio. Por el contrario, el psicodrama insufla creatividad al diseño y ejecución de estas dramatizaciones estructuradas. Así ocurre con el recurso de pacientes simulados (actores entrenados) en los exámenes para estudiantes de medicina en Cataluña y otros países como Inglaterra.

En el campo laboral e institucional se preocupó del análisis de las relaciones interpersonales para el establecimiento de equipos de cuidadores y cuidados o de compañeros de estudio o trabajo. Comenzó en campos de refugiados en Austria en la primera guerra mundial. Sus aportaciones en la selección y diseño de los batallones americanos de la segunda guerra mundial en Washington fue seguido y ampliado por los psiquiatras ingleses que diseña- ron las intervenciones en crisis y sobre todo la psicoterapia de grupo de orientación analítica.

En el plano internacional siempre fue acusado de megalománico. Continuamente se ofrecía para reunir a los grandes líderes mundiales de zonas mundiales en conflicto, invitarlos a intercambiar sus papeles y no salir de la negociación hasta conseguir un acuerdo (5). Parte de esta estrategia se ha seguido para alcanzar algunos acuerdos históricos, como los de Camp David.

En su juventud publicó un libro de poesías, Las Palabras del Padre (6), que comienza diciendo: "Yo soy Dios. El padre, El creador del universo. Estas son Mis palabras. Las palabras del Padre." No resulta extraño el estupor, cuando no desorientación, de sus discípulos. Tampoco parece rara la carencia de una teoría interna, tan sólida y cerrada que pueda prescindir de otras aportaciones. En este sentido su vida y obra son coherentes. Ambas están llenas de chispas de creatividad que se esparcen en el mundo para uso y disfrute de los humanos. Para Moreno, Dios está cuando dos personas se encuentran; lo que confirma su influencia hasídica y panteísta. Cuando Moreno hace al hombre Dios, le responsabiliza de su propia historia. La Tragedia o la Comedia son el resultado de nuestra manera de escribir en el libro de la vida. Nuestra existencia está marcada por la forma de estar en el mundo en lugar del destino, lo inconsciente, los otros, etc, . Esté existencialismo es la base filosófica de sus aportaciones, cuya verdad se encuentra en sus poesías, las cuales han sido malentendidas o menospreciadas por sus discípulos durante décadas. 
ORIGINALES Y REVISIONES

Un aspecto básico para la integración es no perder los objetivos. No se trata de mezclar diferentes técnicas a modo de collage. Más bien se tiene que saber cuales son los fines que se pretenden con la Psicoterapia y después se añade sólo aquello que mejore lo anterior. Se recurre a otra modalidad cuando el logro es insuficiente o no se ajusta al objetivo con el procedimiento habitual. Es preferible rebajar las expectativas del cliente que buscar el " $\mathrm{mi}$ lagro" en las técnicas a emplear.

Por otra parte, cada innovación tiene ventajas e inconvenientes. Al principio, lo nuevo funciona mejor; por lo tanto es preciso determinar cuánto hay de diferente en la técnica en sí, qué grado de entusiasmo irradia el que la aplica y cuánto trasmite a quien lo recibe. La mejor discriminación es la duración del cambio, ya que a los 6 meses $o$ al año la sugestión inicial se agota y se distingue mejor lo que hay de nuevo en dicha intervención.

Es necesaria una formación básica sólida para poder hacer fusiones creadoras. No recomiendo mezclar muchas técnicas al inicio de la formación, porque se corre el riesgo de desconocer su visión del mundo y perder el norte en cada una de ellas. Se debe recurrir a la integración cuando los procedimientos estándares de formación no sirven para resolver las dificultades del cliente. Se añaden aquellas modificaciones de eficacia probada, por su mayor especialización o porque su descripción es más concreta y operativa. La forma diferente de afrontar el problema da una visión más amplia al sufriente. El abordaje innovador suele bastar para la resolución del conflicto.
Estas variaciones se entienden mejor con ejemplos clínicos que con distinciones teóricas. Los primeros muestran la realidad clínica de la interacción, mientras las segundas son fruto de la mente de quién las produce. Finalmente, cuando las diferencias se exponen con la práctica clínica, las disparidades teóricas se empequeñecen, hasta llegar a desaparecer.

\section{3- Psicodrama y psicoanálisis}

Desde el imaginario encuentro entre Moreno y Freud, se han realizado otros no menos seductores como los de Marx y Freud y Marx y Bakunin. Moreno debe a Freud una parte importante de su contribución, pero su paso al grupo y su influencia del teatro le dan una originalidad que normaliza la psicopatología y extiende su influencia a lo social. En una biografía del creador del psicodrama recuerdo la sana envidia que el creador del psicoanálisis tenía de su colega y dramaturgo Schnitzler; éste se anticipaba en sus obras de teatro a las pesquisas que el psicoanalista conseguía tras largas horas de diván y estudio (3). Moreno y Schnitzler trabajaron juntos como dramaturgos en el teatro de la espontaneidad. Era un pequeño teatro de cámara, cerca de la Ópera de Viena, donde se representaban las noticias del día y allí nació el psicodrama (1).

El psicoanálisis aporta la relación discursiva y asociativa, que el psicodrama lleva a la escena y amplía del individuo al grupo y de lo interior al contexto. La dramatización exterioriza y pone en juego lo imaginario, con lo que permite el acceso a lo simbólico, el cual reconstituye los fragmentos perdidos de nuestra existencia. De esta manera, nuestra vida es puesta en pers- 
pectiva y reelaborada bajo un nuevo prisma; el de la creatividad espontánea, que surge cuando la dramatización cala hondo en el protagonista.

No es exacto que el psicodrama sólo trabaje con lo interpersonal y grupal. La relación dual del sujeto consigo mismo también es objeto de su trabajo. Este hecho resulta una sorpresa para muchos psicoterapeutas individuales, para los que el psicodrama sólo es útil en los problemas relacionales y no en los intrapsíquicos. La acción no es el objetivo único del psicodrama, es un elemento más del mismo. La asociación libre inicial de los miembros del grupo permite que el psicodramatista trabaje con las necesidades grupales, más que con las suyas propias. Este caldeamiento inespecífico debe mucho al psicoanálisis. Recurro a él con frecuencia en los grupos de psicoterapia, porque confronta a los sujetos con sus resistencias. Sin embargo es diferente de la asociación libre individual y muestra el salto de lo individual a lo grupal. Una variante clásica es el caldeamiento en racimos, en el que subgrupos comentan sus cosas al inicio de la sesión.

El psicodrama no se reduce sólo a la libre asociación. Existen otras modalidades de ejercicios individuales o grupales para la preparación del grupo: paseos por la escena, estiramientos corporales como desperezarse, bostezar, golpear el suelo, etc. (7). Algunas variantes que practico con cierta asiduidad son: el ensueño dirigido (8) (sirve para un contacto interior y una comunicación más fluida), la representación del ensueño (una variedad psicodramática que enriquece la vivencia) y la dramatización grupal simbólica (indicada en grupos inhibidos o con personas desconocidas entre sí al inicio del grupo, cuando se desea aumentar la cohesividad).

Son dramatizaciones propuestas por el director y deben contar con el apoyo e interés previo del grupo para su realización. Recientemente he creado la agencia de viajes de vida. A lo largo de varias sesiones, los miembros del grupo exponen sus objetivos personales de cambio, el coste que han de abonar para su consecución y diseñan juntos el itinerario grupal. Esta dramatización grupal simbólica aumenta la cohesividad, clarifica los fines comunes y marca el desarrollo futuro del grupo.

La representación exterioriza el mundo intrapsíquico y vuelve a presentar el relacional. Estos hechos son terapéuticos en sí mismos, porque ponen distancia entre el protagonista y su acción, con lo que permiten una reflexión más reposada.

La técnica psicodramática del cambio de roles incrementa la empatía y amplía la visión del mundo. Un ejemplo es el de un joven estudiante que está en psicoterapia de grupo por problemas ansioso depresivos. Es el mayor de 2 hermanos. Durante el divorcio de sus padres testificó a favor de su madre. Su familia vive a 400 $\mathrm{Km}$. de distancia. Él vive con su abuela y se siente presionado para volver con su familia de origen. Me llama por teléfono porque quiere comentarme un tema personal, después de escucharle brevemente le remito al grupo. En la siguiente sesión comenta que su hermana acaba de romper con su novio y él trata de acompañarla. Su novia le dice que se siente menospreciada 
ORIGINALES Y REVISIONES

por su hermana. Concreta esta situación en una comida que prepara su novia para los tres. En ella se aprecian los esfuerzos de su hermana por separarlos. No para de poner cara de asco a todo lo que la novia de su hermano ha cocinado con amor y dedicación. El protagonista, que no entendía bien las quejas de su novia y los motivos de su hermana para semejante comportamiento, es invitado a contemplar la escena desde fuera (técnica del espejo) y desde allí comprende lo que desde la representación no veía. Sobran las interpretaciones. La visión desde fuera le ha proporcionado un insight interior mucho más cercano a su Yo que la interpretación más acertada de un experto psicoterapeuta.

La asociación de escenas, que combina el pensamiento psicoanalítico y psicodramático, lleva a mundos intrapsíquicos inexplorados (9). Una norma del director es acompañar al protagonista, jamás ir por delante de él; ésto es llegar hasta donde él desee. Una novicia, Teresa, lleva un año exclaustrada en la orden contemplativa por sufrir una depresión reactiva. Presenta un conflicto de lealtades entre su familia de origen y su vocación religiosa. Su madre, autoritaria y dominante, anula el deseo de su hija. Asociando escenas del pasado surge una en la que la madre inicia el diseño de una hija cuidadora y anulada. Allí comenzó Teresa a no poder negar nada a su madre. Con el grupo como corifeo, se le insta a gritar “¡NO!". Lo hace con algunas dificultades. Repite ese primer “ $i N O$ !” en varias escenas encadenadas de su biografía: infancia, adolescencia y edad adulta. Pocos días después comenta que ha logrado ser más asertiva con su madre y clarificar su pro- pio deseo. Los compañeros de terapia notan la reversión de la depresión y una mayor participación en la misma.

Otro aspecto inherente a la situación grupal es la resonancia de escenas, donde el inconsciente circula y se refleja en los demás componentes del grupo. Las escenas se encadenan unas con otras en una danza de representaciones que dan coherencia y movimiento a la fase grupal en que se encuentran.

La noción moreniana de coinconsciente, proviene del psicoanálisis, pero su significado trasciende el ámbito individual para llegar al colectivo. Se entiende por coinconsciente cuando dos o más personas tienen una especial afinidad por la cual piensan o sienten lo mismo ante hechos similares, incluso a distancia. Es más una versión en el tiempo presente de los aspectos jungianos de inconsciente colectivo, que un inconsciente freudiano. Conlleva elementos empáticos y de comunicación interpersonal (telerrelación o relación a distancia) que se escapan de la noción freudiana de transferencia, que es una percepción deformada del otro en función de relaciones pasadas. En los grupos evolucionados existen muchos elementos coinconscientes que sorprenden al monitor y expresan los vínculos que unen a sus componentes. Así ocurre cuando un protagonista elige como Yo auxiliar de su escena al miembro del grupo que representa en su vida el mismo papel o que tiene un conflicto similar, sin saberlo de forma consciente.

La pulsión escoptofílica es otra aportación que el psicodrama de los Lemoine hacen desde el psicoanálisis de Lacan. Aun- 
que para mí la fase del espejo de Lacan es la contribución más interesante, no hay duda de que los Lemoine dieron lugar a un psicodrama que va más allá del discurso. Sin embargo, no estoy de acuerdo con su noción de psicoanálisis individual en grupo. La realidad del grupoes más que la suma de los individuos y en el psicodrama individual participan al menos dos personajes, el sujeto y su relación, además del psicoterapeuta. Un ejemplo ilustrativo es el trabajo psicodramático con un psicótico y sus voces en un grupo de personas con trastornos neuroticos. Cada voz se encarna en el cuerpo de una persona. Juntas forman un coro y él es el director. A los asistentes y participantes (en los grupos de terapia los clientes son también Yoes auxiliares) no les resuena este trastorno, tan alejado aparentemente de sus problemáticas. Sin embargo la cohesión grupal y el ambiente de alianza de trabajo mueve a uno de los participantes a compartir: "Yo no tengo esas voces que me ordenan, insultan o me dicen lo que tengo que hacer. Sin embargo pienso que no valgo nada, nadie me quiere, que me voy a morir de una dolencia insignificante, no soy digno de que me tengan en consideración,etc." Le animo a tomar prestada la escena anterior y de ahí surge el taller: el maestro del coro o la canción del sí mismo. El protagonista crea su propia melodía mejorando su autoconcepto, si lo desea, o mantiene su propia visión, como un fúnebre y tenebroso Miserere. En esta escena el sujeto no está apresado por su inconsciente, sino que domina su forma de ser y se responsabiliza de sus actos.

En el psicodrama de los sueños (10, 11) la interpretación y el análisis van más allá del inventor del inconsciente. El di- ván se extiende a toda la sala y al conjunto de su vida. En una primera aproximación el sujeto recrea en la sala su dormitorio, éste aporta multitud de datos sobre su personalidad y forma de ser. Se va a la cama, se desnuda y comienza a dormir. Desde la cama se introduce en el sueño y lo representa. El revivir lo que en el sueño resulta doloroso es una experiencia saludable. Más sano aún es representar los extraños personajes que afloran en el estado onírico. La recreación da un contexto a lo inconexo y otorga un significado a lo oculto. Cuando se llega a esta situación sobran las palabras desde fuera, porque el analista interior ha procesado de forma egosintónica.

El grupoanálisis, que participa de la topología de Lewin, entiende también el grupo como algo más que la suma de individuos. Las fases grupales que describen determinan las actividades más convenientes en cada momento grupal. Estas aportaciones son muy prácticas para el terapeuta grupal y le permiten una lectura del grupo con más de una perspectiva. De hecho, la dramatización de un protagonista, representa a una serie de miembros del grupo y tiene una conexión con el momento grupal, la evolución del mismo y la situación social del país (12). Si embargo, la reducción al ámbito verbal y la noción de acting out (levantarse de la silla) diferencia el grupoanálisis del psicodrama. Este último permite una visión más flexible del dolor humano y una ampliación del repertorio grupoanalítico. El psicodrama recibe del primero una visión más holista del conjunto del grupo y una lectura grupal de la dramatización realizada por un protagonista. 
Raúl Sintes sostiene que en el psicodrama se da el paso de lo siniestro (aquello que nos posee sin que lo sepamos) a lo patético (cuando descubrimos que este poder nos posee) y de éste a lo artístico o maravilloso (cuando lo que nos poseía logramos vencer lo instituido y crear algo nuevo, distinto, la radical novedad del acontecimiento). La representación, la creatividad, el momento y la espontaneidad del psicodrama son las actrices de este proceso que enriquece la práctica psicoterapéutica.

\section{4- Psicodrama y gestalt}

$\mathrm{Si}$ las nociones de Lewin calaron en Moreno, no es menos cierto que éste influyó de forma decisiva en Perls, que asistió con cierta regularidad a las sesiones públicas de psicodrama que Moreno realizaba periódicamente en una sala del Carnegie Hall de Nueva York. A pesar de este hecho, Perls nombra a Moreno casi de pasada.

Sin embargo, las relaciones entre ambas corrientes son muy fecundas. La gestalt propicia el cambio de roles entre la figura y el fondo, es decir entre la persona y su decorado, de forma imaginaria. El psicodrama propone encarnar lo imaginario en el cómo sí de la escena. Es decir, rellenar la silla vacía para adquirir una mayor plenitud de sí mismo.

El introducirse en los objetos (ser los objetos), ha aportado al psicodrama mucha profundidad, como se puede apreciar en el ejemplo siguiente: En un grupo de psicodrama una mujer de 45 años se queja continuamente del fracaso de su ma- trimonio, sin reparar en que la alta exigencia sobre su marido ha acabado por destruirle y sentirse un fracasado. Ella sufre estado continuo de malestar, irritación y crisis de pánico. A pesar de su relato, no acepta su responsabilidad en dicha situación y la proyecta en su pareja, a quien acusa de no saber estar a la altura de las circunstancias. Asocia este relato con el día de su boda. Mientras estaba en la ceremonia nota que le aprieta un zapato. Le pido que encarne ese zapato y comente su vida. ¿Quién lo ha elegido? ¿Para qué lo ha elegido? ¿Qué expectativas suscita ese nuevo matrimonio? ¿Cuál es la realidad de esa nueva pareja?, etc. Con inusitada claridad sale todo el fracaso de la pareja, su dificultad para aceptar las caricias y su goce en el sufrimiento. El zapato se expresa de forma tan clara que muchas de las dudas que había planteado en la psicoterapia de grupo desaparecieron. A partir de ese momento decide mantener las apariencias y no vuelve a necesitar más tratamiento psiquiátrico, a pesar de que durante los últimos 20 años ha realizado alguna visita esporádica.

Otro aspecto capital de la gestalt es el psicodrama de los sueños. El psicodrama clásico comienza por diseñar el dormitorio, meterse en la cama e introducirse en el sueño, como ya he comentado. Cuando el sueño tiene un componente relacional evidente, el resultado es satisfactorio y no se precisa de otros recursos. El volver a soñar en el cómo sí de la escena basta para trasformar el sueño. De esta manera se cumple la frase que Moreno, siendo estudiante, refiere haber dicho a Freud: "Usted analiza los sueños de sus pacientes en el diván y yo les estimulo a que sigan so- 
ñando". La escena se convierte en un inmenso diván donde tienen cabida todos los sueños.

Sin embargo, en ocasiones los recursos habituales del psicodrama no son suficientes o no están indicados; entonces la gestalt (13) resulta un instrumento muy útil (10). La mejor manera de ilustrar esta forma de trabajar es con una viñeta clínica:

En los talleres de psicodrama de los sueños, tras un caldeamiento inespecífico, sugiero que busquen un lugar en la escena donde tumbarse, relajarse y entrar en contacto con sus sueños más habituales. Tras este ensueño dirigido, animo a que los comenten en pequeños grupos y elijan el más significativo. El grupo grande escucha los sueños elegidos y dramatizamos el elegido sociométricamente. Si el seminario es de tipo maratón, la elección sirve para seguir un orden de prioridades.

En uno de estos talleres una joven psi- representa el siguiente sueño: duerme en una cama grande de nogal con su pareja desde hace 8 años, encima de la cama tienen un tapiz con el árbol de la vida. Al entrar en el sueño sale de la cama y va a una habitación que se encuentra poblada de niños muertos, luego va al frigorífico que está lleno de bebés muertos, se acerca al cesto de la ropa sucia y al abrirlo se encuentran un montón de fetos muertos. Esta pesadilla dramática lleva varios meses atormentándola y se despierta con sudoración, taquicardia y sensación de opresión. En el cambio de roles con su pareja, éste trabaja mucho. También ella dedica muchas horas a formarse y encontrar un lugar en su profesión. En el ambiente de la casa se nota una sensación de rutina. La representación del sueño era muy resonante para el público, había varias personas llorando.

Sin embargo, no encuentro algo significativo en la representación. Recurro a la gestalt y sugiero que se convierta en la cama de matrimonio, que explique cuántos años tiene, de dónde proviene y qué es lo que ha visto. Dice ser una cama antigua, que fue escogida por la pareja. Tiene mucha experiencia, han pasado por ella varias familias, y nota que con el paso del tiempo éstas se van separando y le produce dolor. Fue comprada a un anticuario y restaurada con cariño. Al principio dormían muy juntos. Ahora, llegan muy cansados, cada uno se recuesta en un lado. Últimamente ella se despierta con desasosiego y a veces se levanta por la noche.

Como la cama no aporta suficiente información, pido a la protagonista que sea el tapiz del árbol de la vida. Abajo están los durmientes y desde el tapiz la visión que produce resulta más esclarecedora. Fue comprado cuando los dos se fueron a vivir juntos. Desde hace tiempo llegan cansados a la cama, apenas tienen relaciones afectivas y tampoco muestras de cariño. Se escudan en el trabajo, los horarios incompatibles; pero la fuerza de su amor decae. Ella quiere tener un hijo antes de que todo sea tarde, pero no se lo expresa a él. Surge la catarsis de integración. Se da cuenta de su deseo, de la necesidad de cultivar su pareja y conseguir un fruto de la misma.

Le animo a que vuelva a soñar el sueño, ésta es la gran diferencia con el psi- 
coanálisis, y cuando va al frigorífico, recoge un bebé muerto lo lleva a la cama y al calor de los dos le reaniman y cuidan con amor parental.

El eco grupal fue muy resonante y emotivo, a pesar de ser un taller al que asistieron unas 150 personas. Algunas comentaron los abortos y pérdidas recientes y cómo la representación les habían removido las entrañas.

No quisiera acabar sin señalar algunos hechos coinconscientes curiosos. Este taller era la clausura de un acto científico de psicodrama al que había sido invitado. Llevaba dos propuestas: una conferencia sobre "Moreno y las Musas" (1) y el taller citado. Por motivos ajenos a mi voluntad, llegué al final del acto científico y sólo podía dar una de las dos cosas. Decidí plantear la elección al grupo y eligieron el taller.

Para la conferencia llevaba un casete con extractos de música clásica, desde la Viena de finales del siglo XIX a la música moderna dodecafónica, que nació en dicha capital al mismo tiempo que el psicodrama. La selección empieza con valses de los Strauss, música de Mahler, Schönberg y Alban Berg, del último la ópera Lulú, que es el nacimiento de la mujer fatal y el preludio de la mujer moderna, independiente pero innacesible.

La relación con el grupo tenía unas características télicas (relación a distancia que participa de la empatía, la transferencia y la amistad) muy positivas. La coincidencia coinconsciente es que de las dos selecciones de Mahler, una de ellas eran los
Kindertoten lieder (canciones de los niños muertos) que eran lo más apropiado para la representación del sueño. Nadie del grupo sabía qué clase de música llevaba. Finalizamos el taller bailando todos unos valses de los Strauss. De esta manera las Musas de Moreno estuvieron presentes en esta clausura memorable. Todavía hoy, muchos asistentes me recuerdan esta sesión de psicodrama, a pesar de los años transcurridos.

Este ejemplo ilustra claramente cómo la gestalt potencia y desarrolla el psicodrama. Yo recurro a ella con frecuencia en los talleres de crecimiento personal y de esta forma el ensueño dirigido (8) se hace cuerpo y se muestra en la escena, lo que resulta mucho más gráfico y enriquecedor para los asistentes.

El mundo interno y los sentimientos pueden ser materializados. Su exteriorización permite confrontarlos y afrontarlos mucho mejor. Uno se siente menos sólo cuando habla con su soledad. Menos solitario aún si se encarna en su apartamiento y se describe cómo lo inició y cómo lo conserva. Aún menos si vuelve a ser uno mismo, dialoga con la soledad y se pregunta para qué le sirve dicho aislamiento. Se pasa así de un retiro doloroso a uno gozoso o elegido, que puede ser fuente de inspiración para múltiples actividades de la vida, en lugar de una sensación desagradable a evitar.

\section{5- Psicodrama y sistémica}

Moreno fue el primer terapeuta de pareja reconocido. De hechoel psicodrama nace de una psicoterapia de pareja. Aunque sus primeras terapias no fueron tan 
exitosas como él hubiera deseado $(1,3)$, lo cierto es que estos primeros fracasos nos remiten a algo básico: La necesidad de tener en cuenta a los dos protagonistas en la dramatización. El abandono de uno, con la consiguiente inclinación por el otro, puede traer funestas consecuencias. Este doloroso aprendizaje le sirvió para sobrevivir en sus "años de galeras" (1), donde sus lecturas del contexto le llevó a predecir el ganador de los combates de boxeo, en función de los datos relacionales y familiares de los contendientes.

López Barberá y Población (14) definen la escena como sistema. En la representación psicodramática se muestran las interacciones de los protagonistas y sus vidas, que reflejan las del grupo de espectadores y sus propias relaciones interpersonales, éstas son el espejo del momento social en que el grupo se desarrolla.

La escultura mejora el conocimiento y relación de la pareja (14). Básicamente consiste en solicitar a cada uno de los miembros del vínculo que coloque al otro y luego a sí mismo en una postura que exprese sin palabras su relación en un momento determinado. Se trata de una foto de la pareja. Se suele comenzar con la situación del duplo en el presente, luego en el pasado y finalmente en el futuro. Una variante es la relación de pareja en la actualidad, la deseada y la temida. Desde cada una de las esculturas los miembros expresan lo que sienten e intercambian el papel con el otro. Es una aproximación diagnóstica y terapéutica. Es una alternativa muy interesante cuando las palabras y descalificaciones dificultan la comunicación entre los miembros.
Los ciclos evolutivos de la familia diferencian los objetivos terapéuticos con los clientes: Se indica psicoterapia de grupo a una joven estudiante de 21 años, con problemas relacionales con su familia de origen y la extensa. Esta última denunció a sus padres un consumo de drogas no objetivado. Como consecuencia de este estrés sufría una disminución notable de la autoestima con somatizaciones digestivas (su padre era un hombre reservado, que "tragaba" sus sentimientos y padecía una afección digestiva similar). La finalidad de la terapia no es la independencia de su medio familiar, lo que sería una falsa salida y un empobrecimiento futuro. Los objetivos más cercanos son lograr una confianza en sí misma y una apertura a los demás que permita exprese sus deseos y logre ser escuchada por sus padres. También es importante que consiga habilidades suficientes de negociación para seguir estudiando, acabar su carrera y tomar decisiones afectivas propias. Estos mismos objetivos no son adecuados para un profesional liberal exitoso de 35 años, el único soltero de la casa de sus padres, que acude al mismo grupo. Ha sufrido un cuadro psicótico paranoide referencial de perjuicio $y$ ha vuelto a refugiarse en casa de sus padres, abandonando los contactos sociales y la vida independiente que llevaba.

La visión relacional proporciona fondo a las escenas que los protagonistas nos presentan y clarifican mucho el futuro. Una joven estudiante, hija única, duda entre su antiguo novio, que la había dejado por otra y ahora pugnaba por volver, $y$ el actual, que no es aceptado por sus padres debido a su amaneramiento e independencia. Ambos son compañeros de pro- 
ORIGINALES Y REVISIONES

fesión. El primero se apoya en ella para acabar su carrera y la maltrata psicológicamente. De ideas tradicionales, tiene una excelente relación con los padres de ella. El segundo, le anima a ella para que finalice su carerra, trabaje y abandone el negocio familiar donde se ha refugiado. Las dudas e inseguridades al respecto y su baja autoestima le producen un cuadro depresivo con desmotivación, falta de rendimiento académico, ideas de muerte, indecisiones, labilidad afectiva, etc. En la dramatización se avanza $1,5,10$ y 20 años de futuro con cada uno de los dos candidatos (técnica de proyección al futuro). El grupo no tiene duda de que el segundo novio le proporcionará una vida personal y profesional más armónica e independiente. $\mathrm{El}$ primero exige que sea ama de casa, renuncie a sus éxitos académicos y soporte sus huídas de casa y sus juergas.

Ella necesitó 6 meses más de psicoterapia grupal para poder vislumbrar lo que era evidente para todos los asistentes. Actualmente lleva varios años felizmente casada con el segundo novio y acaba de tener un hijo. Las razones para esta disparidad son que la dramatización se realizó al inicio del grupo y ella no estaba preparada para objetivar dichas diferencias y sobre todo para romper con los lazos de protección parental que dicha decisión conlleva.

Algo similar ocurrió con una pareja que llevaba una década de convivencia sin consolidar. La proyección tres décadas adelante, deshizo la disculpa perenne de las comisiones de servicio y la inseguridad en el puesto de trabajo. Actualmente se encuentran casados y tiene varios hijos, así como un trabajo estable para los dos.
La técnica del espejo permite que el protagonista observe la acción desde fuera. Puede objetivar mejor cómo los reiterados intentos fallidos de solución se convierten en un auténtico problema. Fomenta el desarrollo de nuevas respuestas o la corrección de las antiguas.

La vida futura sin problemas se concreta mucho mejor cuando se representa en la escena, con lo que el psicodrama se adelanta varias décadas a la terapia familiar breve centrada en soluciones.

Cuando el protagonista pasa por los diversos papeles de su átomo familiar o social, completa su sistema relacional y adquiere una percepción más clara de su situación. A veces esta identificación es suficiente para que el sujeto rectifique su antigua forma de actuar. Así le ocurrió a una joven que durante varios años mantenía una relación tormentosa con un varón varios años mayor. Éste la seducía y al día siguiente se presentaba con otra. Cuando ella se alejaba, él volvía a acercarse. El ciclo se repetía continuamente. El paso por cada uno de los papeles aumentó su capacidad de decisión.

Otra mujer de 29 años, cuando está con su novio desea un hombre imposible. Se queja del abandono del primero, que nota el alejamiento de ella y recurre al alcohol y cocaína. La escena se desarrolla en un bar. Los protagonistas son su novio, el hombre imposible, que es el camarero, y ella. Como botella encima de la barra elige una chica muy atractiva del grupo. Ella está mirando continuamente al otro hombre, cuando cambia de papeles se da cuenta de su juego. Asume su responsabi- 
lidad, en lugar de la defensa proyectiva que hasta ahora realizaba. A partir de entonces abandona el juego relacional y se dedica a ir con su novio a un centro de tratamiento de adicciones sociales.

En mi práctica diferencio mucho cuando hago terapia familiar y psicodrama, como si fueran dos encuadres distintos. Sin embargo, la visión sistémica da a mi trabajo psicodramático una amplitud de miras que se extiende a los ciclos familiares y a las familias de origen, así como la estructura relacional de la familia, lo que jerarquiza mejor los objetivos. La visión psicodramática otorga a la terapia familiar una actuación más flexible y menos rígida, donde la creatividad sirve para el fomento de la comunicación de los afectos en las familias.

\section{6- Psicodrama y técnicas corporales}

El cuerpo del terapeuta y de los asistentes al psicodrama es mostrado en toda su extensión. Aunque no es el eje, sí es el motor de la existencia. La dramatización cuando comienza en frío resulta poco creíble, no cala en los espectadores y los actores actúan de forma distanciada y carente de emoción. Por eso siempre recurro a técnicas de caldeamiento verbales y corporales.

Los actores profesionales antes de la representación hacen ejercicios físicos de preparación, tanto del cuerpo como de la voz, para poder moverse mejor e impostar el sonido. De esta manera, hasta los susurros llegan a lo más recóndito de la sala. Los movimientos corporales de estiramiento 6 de relajación sirven para poder introducirse en el papel y hacer una representación fluída. El maquillaje y el vestuario contribuyen a sumergirse en el personaje y hacerlo creible.

En psicodrama cada vez se trabaja menos con esta preparación. Sólo el teatro espontáneo invierte esfuerzo en esta imprescindible preparación inicial; lo que es un recordatorio hacia una tarea necesaria en el psicodrama. Cuando encuentro al grupo muy rígido, recurro a la escena caótica y juguetona de moverse con rapidez por la sala y toparse con los hombros con los otros miembros del grupo. Sin la obligación de decir «perdon» 0 «lo siento», las risas y el calor que generan estos choques trasforman la atmósfera inicial del grupo.

Pero lo corporal no se desarrolla sólo en la fase inicial de la sesión. En la dramatización el cuerpo interacciona con los otros. Son clásicos los ejercicios grupales de reconocimiento a ciegas por medio del tacto, donde la palabra y la vista están excluidas. También aquellos de fuerza, por ejemplo empujar al compañero/a con las palmas de las manos 6 gritar " $i N O$ !" e intimidar gestualmente al contrario sin tocarle. El reconocimiento del otro por el olor o utilizar una fragancia como iniciador de un encuentro son otras formas de activar las reacciones de un grupo.

Recuerdo un grupo en el que representamos El Beso de Gustav Klimt, cuyo póster está en la cabecera de la cama de la protagonista, expresando el anhelo de amor por su pareja. En la sesión siguiente llevé unas láminas de Klimt y otras de su discípulo Egon Schiele, el grupo eligió la representación de uno de eso bellos paisajes que Schiele pintó y que se encuentran muy ale- 
jados de sus autorretratos expresionistas. Los árboles, el camino y el arroyo, hecho con los cuerpos de los asistentes, hablaron mucho de cada uno y de su posición en el grupo y/o en la vida, constituyendo una de las sesiones más productivas de ese grupo.

La maximización, exageración deliberada de una postura o gesto, ayuda en muchas dramatizaciones a ser consciente de lo que subyace bajo el guión de la representación, de ahí la enorme utilidad que tiene para el director.

La bioenergética aporta formas de andar, respirar y liberar la cadera, que son útiles preparatorios para una mayor flexibilidad corporal o para una lectura de las zonas contracturadas del cuerpo. Los ejercicios de descarga de agresividad derivada hacia objetos son también necesarios en algún momento de la dramatización.

La relajación con técnicas de respiración y de contracción-relajación, siguiendo la teoría de inhibición recíproca de Wolpe, es un recurso grupal útil para los pacientes ansiosos. Igual ocurre con las técnicas sofrológicas o la relajación de Jakobson.

En terapia sexual prima el uso del tacto, uno de los sentidos más prohibidos e ignorados y por lo tanto poco practicados en la vida y en la psicoterapia. El masaje sensitivo gestáltico busca el contacto y la relación por medio de las manos y experiencias táctiles. El psicodrama simboliza la experiencia placentera y da permiso al goce, incluso allí donde está más reprimido. En grupos de terapia o de crecimiento personal recurro a estas técnicas en contadas ocasiones, cuando lo hago son grupos evolucionados y que plantean dicha demanda. Suelo comenzar por ejercicios grupales de caldeamiento, por ejemplo contactar en grupos sentados en el suelo y con los ojos cerrados, sólo con las manos, después sólo con los pies. Finalmente en dos ruedas concéntricas de pie, la de afuera conecta con las manos de la interior que recibe pasivamente con los ojos cerrados. La exterior va ascendiendo por el brazo y antebrazo hasta la cara y vuelve poco a poco hasta las manos despidiéndose en silencio. Se hacen varios cambios de pareja, permaneciendo el círculo interior siempre con los ojos cerrados. Después se intercambian los papeles. En otras ocasiones les pido elección por parejas y aprenden a respirar con el vientre, moviendo las caderas tal y como se enseña en bioenergética, en decúbito supino, con las piernas flexionadas, al inspirar dirigen las caderas hacia el suelo y al espirar giran las caderas hacia el techo. El ayudante con las manos en las caderas ayuda a su movilización. Tras estos ejercicios prosigo con un amplio comentario grupal que permita procesar las emociones y experiencias del grupo.

Hace años realicé el siguiente taller: "El goce del cuerpo - encuentro en el jardín secreto", dirigido a los profesionales de un encuentro de psicodrama. Advierto que es preciso acudir con bañador o estar dispuestos a desprenderse la ropa y realizar parte del taller en paños menores.

La idea surgió de una experiencia similar con un terapeuta reichiano. Durante 45 minutos hablando de la necesidad de quitarse la ropa, de hacer el taller desnudo, etc. Aburrido de lo prolijo del discurso le pregunto si podemos empezar a quitarnos la ropa e iniciar el taller. Los asisten- 
ORIGINALES Y REVISIONES

tes respiran con alivio y todos nos desnudamos, excepto el monitor que a los calzoncillos de rigor añadió una camiseta.

El número de asistentes a mi taller es limitado, en la puerta de la sala hay una cartulina. Al llegar veo que no hay ningún nombre apuntado y supongo que la experiencia es demasiado fuerte para el psicodrama. No obstante atravieso la puerta y me encuentro con 12 personas dispuestas a realizarlo. Tras unos ejercicios de caldeamiento, ya descritos, que sirvien para desprenderse poco a poco de la ropa, les pido una elección por parejas. Realizan respiración bioenergética por parejas y después se pasan por el cuerpo la ropa que se habían quitado. Cuando acaban el cambio de roles, pido a las parejas que compartan sus sentimientos $e$ imaginen una escena que simbolice el encuentro. Describen una playa, acariciados por el sol, un fondo marino con los peces acariciando los cuerpos, etc.

La escena elegida sociométricamente es la de un convento de monjas, donde el cura se enamora de una novicia. Se citan en la iglesia. Es de noche, la novicia sale de la celda y encuentra a su amado en el altar, se besan apasionadamente y se desnudan. Él la tiende sobre el altar y pasa los manteles del mismo por su cuerpo. El encuentro destila un intenso erotismo que inunda a todos los asistentes que se manifiesta en el comentario final. No se trata de una profanación de lo sagrado, sino una sacralización del placer, donde los dioses somos nosotros mismos, más allá de las prohibiciones y convenciones sociales. Todo el grupo agradeció el trato delicado y la forma progresiva de entrar en situación, así como lo placentero de la experiencia.

\section{6- Conclusiones}

- La integración de diversas técnicas permite ampliar el punto de vista de la base teórica inicial.

- La integración no es mera adición de una teoría sobre otra, si se hace tiene que ser bajo un porqué o un para qué. Siempre estas respuestas han de superar a la técnica básica.

-Se requiere un amplio conocimiento de la teoría básica, para permitir otra intervención, sin riesgo de desvirtuar la teoría inicial.

- La mejor manera de mostrar la utilidad de las integraciones teóricas es cuando se ve o se describe como se hace, con ejemplos concretos.

- Las oposiciones entre las teorías suelen ser más marcadas en los comienzos de su desarrollo, para notar las diferencias y resaltar su originalidad. Pasado este momento inicial pueden ser integradas sin obstáculo alguno.

- Cuando las diferencias se muestran en lugar de discutirlas, las distancias disminuyen de manera notable y se pueden aprender formas distintas de afrontar los problemas.

- Se requiere una dosis de seguridad sobre la teoría básica que sostiene la clínica y una gran flexibilidad y humildad para reconocer las insuficiencias manifiestas de todas las teorías y, por lo tanto, sus posibilidades de superación y/o mejora.

- La integración de diversos modelos de psicoterapia previene el fundamentalismo teórico de una sola, al que suele asociarse la absoluta ignorancia y desprecio de los muy diversos puntos de vista que intentan aprehender la realidad. 
ORIGINALES Y REVISIONES

\section{BIBLIOGRAFIA}

(1) Espina Barrio J.A. Psicodrama: Origen y Desarrollo, Salamanca, Amarú, 1995.

(2) Espina Barrio J.A “Aproximación Psicodramática a las Psicosis”, Rev. A.E.N., 1989, IX, 20, pp. 219-228.

(3) Marineau R.F. Jacob Levy Moreno1889-1974. Father of Psychodrama, Sociometry and Group Psychotherapy, Londres y Nueva York, Tavistock. Routledge, 1989.

(4) Greenberg I.A. Moreno y el Psicodrama-Biografía e historia, Buenos Aires, Hormé-Paidós, 1977.

(5) Moreno J.D. “The Autobiography of J.L. Moreno, MD (Abridged)”, J. Group Psychotherapy, Psychodrama and Sociometry, 1989, 42, 1 y 2, pp. 3-126.

(6) Moreno J.L. Las Palabras del Padre, Buenos Aires, Vancu, 1976.

(7) Población Knappe P. Teoría y Práctica del Juego en Psicoterapia, Madrid, Fundamentos, 1997.

(8) Stevens J.O. El Darse Cuenta, Sentir, Imaginar, Vivenciar, Santiago de Chile, Cuatro Vientos Editorial, 1988.

(9) Espina Barrio J.A. «Lo Imaginario en la Escena Psicodramática”, Informaciones Psiquiátricas, 1991/1992, 126-127, pp. 355-364.

(10) Espina Barrio J.A. «Psicodrama de los Sueños. Integración de Psicoanálisis, Psicodrama y Gestalt, Rev. A.E.N., Vol. XI, N 38, 1991, pp. 197-201.

(11) Leutz G. "The Psychodramatic Treatment of Dreams", Group Analysis, Vol. 19, 1986.

(12) Bustos D.M. Nuevos Rumbos en Psicoterapia Psicodramática. Individual, parejas y grupo en función social, La Plata (Argentina), Momento, 1985.

(13) Perls F. Sueños y Existencia. Terapia Gestáltica, Santiago de Chile, Cuatro Vientos Editorial, 1974.

(14) López Barberá E. y Población Knappe P. La escultura y otras técnicas psicodramáticas aplicadas en psicoterapia, Barcelona, Paidos, 1997.

*Centro Salud Mental Parquesol

C/ Ciudad de la Habana, s/n

47014 VALLADOLID

Tfno: 983307753

Fax: 983380386

E-Mail: csm.parquesol@pulso.com

Fecha de recepción: 1-IX-1999 